\title{
Clinical and laboratory characteristics associated with dyslipidemia and liver steatosis in chronic HBV carriers
}

\author{
Angélica Luciana Nau ${ }^{[1]}$, Júlia Cristina Soares ${ }^{[1]}$, Maria Beatriz Cacese Shiozawa ${ }^{[2]}$, \\ Esther Buzaglo Dantas-Corrêa ${ }^{[1]}$, Leonardo de Lucca Schiavon ${ }^{[1]}$ \\ and Janaína Luz Narciso-Schiavon ${ }^{[1]}$
}

[1]. Núcleo de Estudos em Gastroenterologia e Hepatologia, Departamento de Clínica Médica, Universidade Federal de Santa Catarina, Florianópolis, SC. [2]. Departamento de Patologia, Universidade Federal de Santa Catarina, Florianópolis, SC.

\begin{abstract}
Introduction: Chronic hepatitis B virus (HBV) infection and liver steatosis (LS) are the most common causes of chronic liver disease, and their coexistence is frequently observed in clinical practice. Although metabolic syndrome is the main cause of LS, it has not been associated with HBV infection. The aims of this study were to describe the lipid profile and prevalence of LS among HBV carriers and to identify the characteristics associated with LS in this group. Methods: This retrospective cross-sectional study included hepatitis B surface antigen (HBsAg)-positive patients evaluated during 2011 and 2012 . Results: Of the 83 patients included, the mean age was $46.4 \pm 12.5$ years, $53 \%$ were men, and $9.1 \%$ were hepatitis B e antigen (HBeAg) -positive. These patients exhibited the following lipid profile: total cholesterol $=175.4 \pm 38.8 \mathrm{mg} / \mathrm{dL}$, low-density lipoprotein $(\mathrm{LDL})=113.0 \pm 32.7 \mathrm{mg} / \mathrm{dL}$, and triglycerides $=91.1 \pm 45.2 \mathrm{mg} / \mathrm{dL}$. Their fasting glucose was $95.3 \pm 14.5 \mathrm{~g} / \mathrm{dL}$, and fasting insulin was $6.1 \pm 5.9 \mu \mathrm{IU} / \mathrm{mL}$. Liver steatosis was observed on abdominal ultrasound in $11.3 \%$ of individuals. Factors associated with the presence of LS included higher levels of total cholesterol, prothrombin activity, fasting insulin, and body mass index (BMI) as well as lower levels of aspartate aminotransferase (AST). Conclusions: These findings suggest that LS in patients with chronic HBV appears to be a consequence of metabolic alterations and insulin action rather than of viral factors.
\end{abstract}

Keywords: HBV. Hepatitis B. Fatty liver. Lipids. Cholesterol. Triglycerides.

\section{INTRODUCTION}

Chronic hepatitis B virus (HBV) infection and liver steatosis (LS) are the most common causes of chronic liver disease. An estimated 350 million individuals are chronically infected with HBV worldwide ${ }^{1}$. The lack of specific and sensitive noninvasive diagnostic tests for LS limits the ability to reliably detect the disease and determine its real prevalence. Often, non-alcoholic fatty liver disease (NAFLD) is diagnosed presumptively when imaging studies suggest the presence of LS or when elevated liver enzymes are noted in overweight or obese individuals with no other identifiable cause of liver disease ${ }^{2}$. For many patients, LS is indolent; however, approximately one-third of patients progress to cirrhosis and, in some cases, liver failure. Patients with simple LS may progress to steatohepatitis and cirrhosis ${ }^{3}$.

It has been established that chronic hepatitis $\mathrm{C}$ is closely associated with LS, insulin resistance, and an increased risk

\footnotetext{
Address to: Dr ${ }^{\mathrm{a}}$ Janaína Luz Narciso-Schiavon. Dept ${ }^{\circ}$ Clínica Médica/HU Polydoro Ernani de São Thiago/UFSC. R. Professora Maria Flora Pausewang $\mathrm{s} / \mathrm{n}^{\circ} / 3^{\circ}$ Andar, Trindade, 88040-900 Florianópolis, SC, Brasil.

Phone: 5548 3721-9014

e-mail: janaina.narciso@uol.com.br

Received 21 January 2014

Accepted 10 April 2014
}

of type 2 diabetes. Although these associations may be a consequence of metabolic factors, the hepatitis $\mathrm{C}$ virus itself has the capacity to promote steatosis and insulin resistance ${ }^{4}$. However, metabolic syndrome has not been associated with HBV infection ${ }^{5,6}$.

It has been demonstrated that HBV carriers have decreased levels of total cholesterol, high-density lipoprotein, and lowdensity lipoprotein, suggesting that HBV infection counteracts dyslipidemia $^{7-10}$. Moreover, LS in chronic HBV patients is associated with changes in anthropometric indices and metabolic factors but not HBV itself ${ }^{11}$.

Factors affecting the development of LS in patients with chronic HBV infection remain obscure, although clinical observations report the common coexistence of both diseases ${ }^{12,13}$. Additionally, data are lacking on this subject in Brazil. This study aimed to evaluate the prevalence of LS and examine the lipid profiles of chronic HBV carriers, as well as to compare the clinical features and lipid profiles among individuals with chronic HBV infection with and without LS.

\section{METHODS}

This descriptive, retrospective cross-sectional study included consecutive adult patients who tested positive for hepatitis B surface antigen $(\mathrm{HBsAg})$, presented at the Gastroenterology and 
Hepatology Outpatient Clinic of the University Hospital of the Federal University of Santa Catarina between August 2011 and September 2012, and provided their written informed consent to participate in the study. Patients with incomplete clinical or laboratory data in their medical records were excluded from the study. A diagnosis of hepatocellular carcinoma was also a cause for exclusion.

Clinical, laboratory, and histological findings were collected from data contained in the medical records. The patient records were analyzed for the following clinical and demographic characteristics: gender, age, comorbidities (diabetes mellitus, dyslipidemia, and hypertension), current antiviral therapy, and body mass index (BMI). The laboratory variables analyzed included the following: hepatitis $\mathrm{B}$ e antigen ( $\mathrm{HBeAg}$ ), hepatitis B virus-deoxyribonucleic acid (HBV-DNA), alpha-fetoprotein (AFP), creatinine, hemoglobin, platelets, prothrombin activity, albumin, direct bilirubin, aspartate aminotransferase (AST), alanine aminotransferase (ALT), alkaline phosphatase (ALP), gamma-glutamyltransferase (GGT), total cholesterol, high-density lipoprotein (HDL), low-density lipoprotein (LDL), triglycerides, glycemia, fasting insulin, and glycated hemoglobin. Biochemical test results were expressed as absolute values. The hepatic biochemistry tests, including the levels of AST, ALT, ALP, and GGT, were expressed as a multiple of the upper limit of normal $(\times \mathrm{ULN})$. Laboratory tests performed within 6 months of the date of the ultrasound were used for this study. The levels of HBV DNA were measured using an in-house real-time quantitative polymerase chain reaction (qPCR) assay with a lower limit of detection of $20 \mathrm{IU} / \mathrm{ml}$. The most recent level of HBV-DNA was considered for inclusion in the study. Some patients were taking nucleos $(t)$ ide analogues when their levels of HBV-DNA were tested.

Ultrasound data were collected from the medical records. An upper abdominal ultrasound is routinely performed for all patients positive for HBsAg to screen for hepatocellular carcinoma. A liver biopsy is indicated for all patients positive for $\mathrm{HBeAg}$, regardless of their ALT levels. Patients negative for $\mathrm{HBeAg}$ with elevated ALT and/or a high viral load $(\geq 2,000.0 \mathrm{IU} / \mathrm{mL})$ are also subjected to a liver biopsy. According to the National Consensus on the Classification of Chronic Hepatitis $^{14}$, the following histological characteristics were examined during the liver biopsies: advanced fibrosis (defined as structural changes of stage 3 or 4 ) and marked inflammatory activity (defined as periportal activity of stage 3 or 4).

Continuous variables were compared using Student's t test or the Mann-Whitney U test when appropriate. Categorical variables were compared using the chi-square test or Fisher's exact test. Univariate analysis was used to identify characteristics associated with the presence of liver steatosis (either on abdominal ultrasound or from the liver biopsy). The correlation between the liver biochemistry results and lipid profile (total cholesterol, HDL, LDL, and triglycerides) was assessed using Pearson's correlation coefficient. The level of statistical significance adopted was $5 \%(p$-value $<0.05)$. All tests were two-tailed and conducted using the statistical software Statistical Package for the Social Sciences (SPSS) version 17.0 (SPSS Inc., Chicago, Illinois, USA).

\section{Ethical considerations}

The study protocol conformed to the ethical guidelines of the 1975 Helsinki Declaration and was approved by the review board of the Federal University of Santa Catarina under the number 131.513 .

\section{RESULTS}

\section{Patient characteristics}

From August 2011 to September 2012, 112 patients infected with HBV were considered for enrollment. Twenty-two individuals were excluded from the study due to lack of a lipid profile; four patients had no record of an abdominal ultrasound; and three had hepatocellular carcinoma (Figure 1).

The characteristics of the 83 consecutive patients fulfilling the entry criteria are summarized in Tables $\mathbf{1}$ and $\mathbf{2}$. The mean age was $46.4 \pm 12.5$ years; $53 \%$ of the patients were men; and $9.1 \%$ of the patients were $\mathrm{HBeAg}$ positive. The laboratory values, expressed as mean \pm standard deviation (median), were ALT $0.9 \pm 0.1(0.6) \times \mathrm{ULN}$, albumin $3.9 \pm 0.4(3.9) \mathrm{g} / \mathrm{dL}$, prothrombin activity $83.3 \% \pm 14.9 \%(85.2 \%)$, and platelets $192,036.1 \pm 68,939.8(182,000.0) / \mathrm{mm}^{3}$. The lipid profile results, expressed as mean \pm standard deviation (median), were total cholesterol 175.4 \pm 38.8 (176.0)mg/dL, HDL 47.1 \pm 12.9 (45.0) $\mathrm{mg} / \mathrm{dL}, \mathrm{LDL} 113.0 \pm 32.7(112.0) \mathrm{mg} / \mathrm{dL}$, and triglycerides $91.1 \pm 45.2(79.0) \mathrm{mg} / \mathrm{dL}$. The fasting glucose was $95.3 \pm 14.5$ (93.0)g/dL, fasting insulin $6.1 \pm 5.9(4.1) \mu \mathrm{IU} / \mathrm{mL}$, and glycated hemoglobin $6.0 \% \pm 1.3 \%(5.7 \%)$. Steatosis of the liver was observed on abdominal ultrasound in $11.3 \%$ of the individuals. Among 39 individuals subjected to liver biopsy, steatosis was present in $41 \%(\mathrm{n}=16)$.

\section{Correlation between liver biochemistry and lipid profile test results}

A positive correlation was observed between the platelet count and total cholesterol $(\mathrm{r}=0.284 ; \mathrm{p}=0.01)$ and $\mathrm{LDL}(\mathrm{r}=0.35 ; \mathrm{p}<0.01)$.

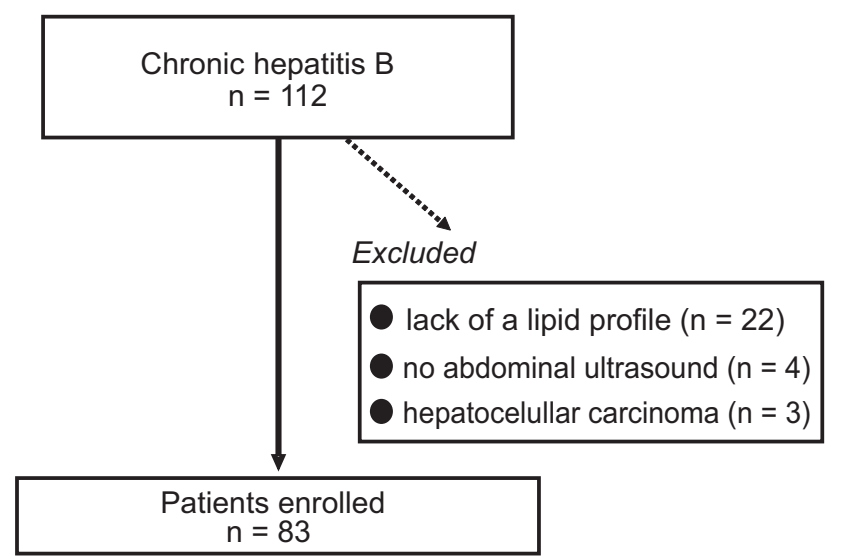

FIGURE 1 - Flow diagram of the potential candidates for participation in the study, criteria for exclusion, and subjects enrolled. 
A positive correlation was also observed between serum albumin and total cholesterol $(\mathrm{r}=0.257 ; \mathrm{p}=0.03)$ and LDL $(\mathrm{r}=0.34$; $\mathrm{p}<0.01)$. Prothrombin activity was positively correlated with the total cholesterol $(\mathrm{r}=0.355 ; \mathrm{p}<0.01)$ and triglycerides $(\mathrm{r}=0.296$; $\mathrm{p}=0.02$ ).

Negative correlations were observed between AST and total cholesterol $(r=-0.314 ; \mathrm{p}<0.01)$, HDL $(\mathrm{r}=-0.246$; $\mathrm{p}=0.03)$, and LDL $(\mathrm{r}=-0.264 ; \mathrm{p}=0.03)$. Negative correlations were also observed between direct bilirubin and total cholesterol $(\mathrm{r}=-0.396 ; \mathrm{p}<0.01)$, LDL $(\mathrm{r}=-0.391 ; \mathrm{p}<0.01)$ and triglycerides $(\mathrm{r}=-0.285 ; \mathrm{p}=0.02)$.

No correlation was observed between ALT, ALP, GGT, and the lipid profile results or between HBV-DNA and the lipid profile results.

TABLE 1 - Clinical and laboratory characteristics of 71 patients with hepatitis B infection according to the presence of hepatic steatosis on ultrasonography.

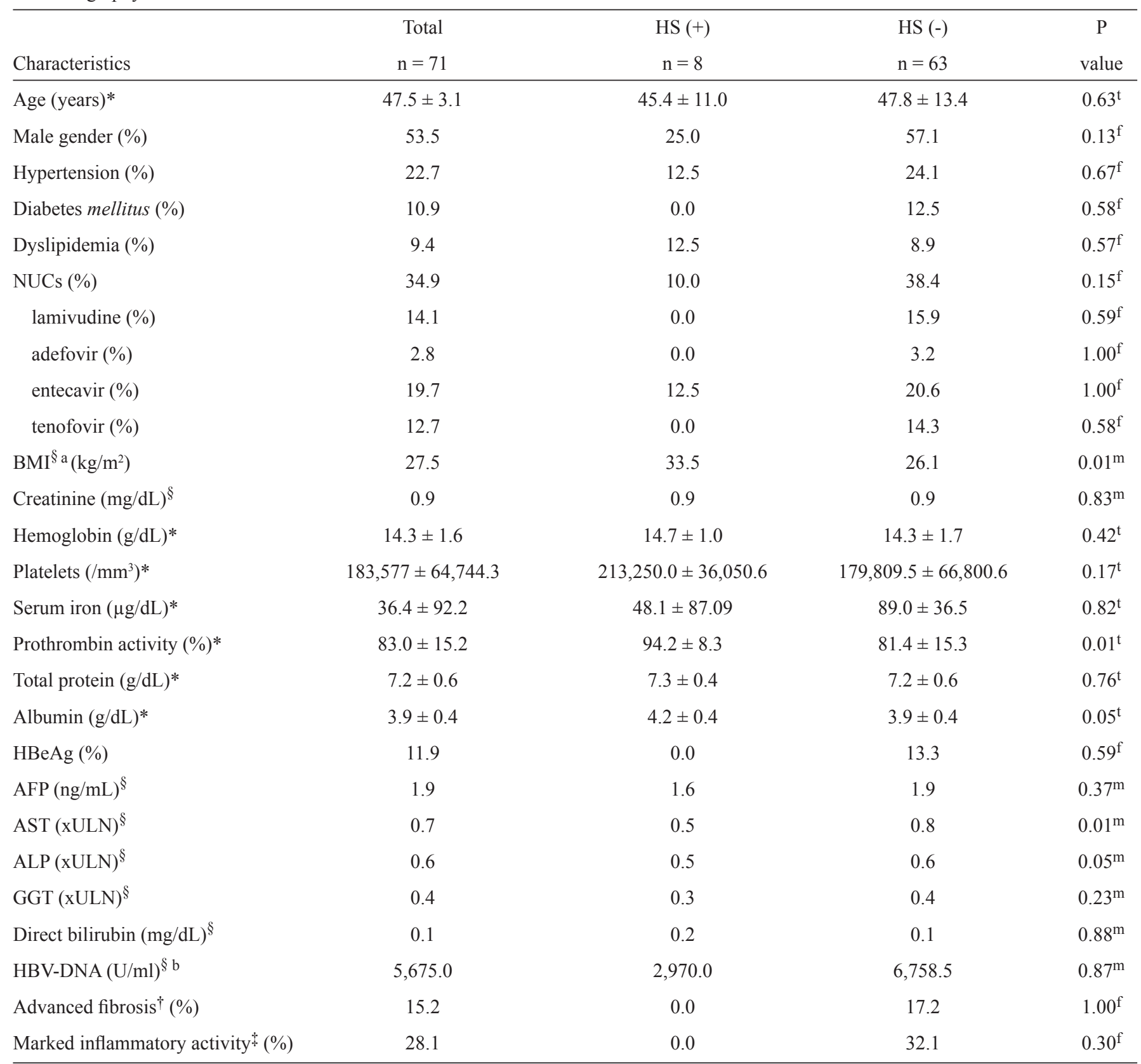

HS: hepatic steatosis; NUCs: nucleoside or nucleotide analogues; BMI: body mass index; HBeAg: hepatitis B e antigen; AFP: alpha-fetoprotein; AST: aspartate aminotransferase; ALT: alanine aminotransferase; ALP: alkaline phosphatase; GGT: gammaglutamyltransferase; xULN: times the upper limit of normal; HBV-DNA: hepatitis B virus-deoxyribonucleic acid. *mean \pm standard deviation; \$median; 'Student's $t$ test; mMann-Whitney U test; fFisher's exact test; †advanced fibrosis = structural changes of stage

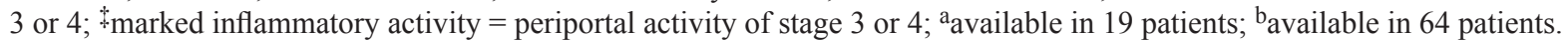


TABLE 2 - Lipid profile of 71 patients with hepatitis B infection according to the presence of hepatic steatosis on ultrasonography.

\begin{tabular}{lccc}
\hline & Total & HS $(+)$ & HS (-) \\
Characteristics & $\mathrm{n}=71$ & $\mathrm{n}=8$ & $\mathrm{n}=63$ \\
\hline Total cholesterol $(\mathrm{mg} / \mathrm{dL})^{*}$ & $173.8 \pm 39.7$ & $217.5 \pm 41.2$ & $168.2 \pm 36.2$ \\
HDL $(\mathrm{mg} / \mathrm{dL})^{*}$ & $47.6 \pm 3.5$ & $45.6 \pm 5.4$ & $47.9 \pm 14.2$ \\
LDL $(\mathrm{mg} / \mathrm{dL})^{\S}$ & 109.5 & 135.0 & 104.0 \\
Triglycerides $(\mathrm{mg} / \mathrm{dL})^{\S}$ & 77.5 & 116.5 & $0.40^{\mathrm{t}}$ \\
Fasting glucose $(\mathrm{mg} / \mathrm{dL})^{\S \mathrm{a}}$ & 93.0 & 98.0 & $0.01^{\mathrm{m}}$ \\
Fasting insulin $(\mu \mathrm{IU} / \mathrm{mL})^{\S \mathrm{b}}$ & 3.5 & 9.2 & $0.05^{\mathrm{m}}$ \\
Glycated hemoglobin $(\%)^{\S \mathrm{c}}$ & 5.8 & 5.8 & $0.86^{\mathrm{m}}$ \\
\hline
\end{tabular}

HS: of hepatic steatosis; HDL: high-density lipoprotein; LDL: low-density lipoprotein; * mean \pm standard deviation; ${ }^{\S}$ median; ${ }^{t}$ Student's $t$ test; mann-Whitney U test; a available in 69 patients; bavailable in 31 patients; ${ }^{c}$ available in 36 patients.

\section{Factors associated with the presence of liver steatosis on abdominal ultrasound}

Patients with LS, compared to those without steatosis on abdominal ultrasound, exhibited a higher mean total cholesterol (201.7 \pm 50.4 vs. $171.8 \pm 35.9 \mathrm{mg} / \mathrm{dL}$, respectively; $\mathrm{p}=0.02)$, greater prothrombin activity $(94.1 \pm 7.9 v s .81 .6 \pm 15.1 \mathrm{mg} / \mathrm{dL}$; $\mathrm{p}<0.01)$, a higher median fasting insulin $(9.2 \mathrm{vs} .3 .3 \mathrm{mg} / \mathrm{dL}$; $\mathrm{p}=0.04)$, and a higher median BMI ( $\left.33.5 v s .26 .3 \mathrm{~kg} / \mathrm{m}^{2} ; \mathrm{p}=0.01\right)$. Patients with LS also showed lower median AST levels on abdominal ultrasound compared to those without steatosis ( 0.5 vs. $0.8 \times \mathrm{ULN}$, respectively; $\mathrm{p}=0.02$ ) (Tables 1 and $\mathbf{2}$ ).

No differences were found on ultrasound between individuals with or without LS with regard to age, gender, skin color, history of hypertension, diabetes or dyslipidemia, antiviral therapy, HBeAg, HBV-DNA, AFP, creatinine, hemoglobin, platelets, direct bilirubin, ALT, ALP, GGT, HDL, LDL, triglycerides, or fasting glucose (Tables $\mathbf{1}$ and 2). Neither the presence nor the absence of LS on abdominal ultrasound was correlated with advanced fibrosis or marked periportal inflammatory activity.

\section{Factors associated with the presence of steatosis on liver biopsy}

Only 39 individuals were subjected to liver biopsy. Only two of these patients were HBeAg-positive, and $16(41 \%)$ presented LS on biopsy. When patients with steatosis were compared to those without steatosis on liver biopsy, no differences were observed with regard to age $(\mathrm{p}=0.59)$, gender $(\mathrm{p}=0.24)$, skin color $(\mathrm{p}=0.63)$, history of hypertension $(\mathrm{p}=1.00)$, diabetes $(\mathrm{p}=1.00)$, dyslipidemia $(\mathrm{p}=0.62)$, antiviral therapy $(\mathrm{p}=0.43)$, BMI $(p=0.12), \operatorname{HBeAg}(p=0.51), \operatorname{HBV}-D N A(p=0.53)$, platelets $(p=0.54)$, direct bilirubin $(p=0.43)$, AST $(p=0.19)$, ALT $(p=0.82)$, ALP $(p=0.23)$, GGT $(p=0.93)$, total cholesterol $(\mathrm{p}=0.95), \operatorname{HDL}(\mathrm{p}=0.23), \mathrm{LDL}(\mathrm{p}=0.75)$, triglycerides $(\mathrm{p}=0.33)$, and fasting glucose $(p=0.69)$. Neither the presence nor the absence of LS on biopsy was correlated with advanced fibrosis $(\mathrm{p}=0.37)$ and marked periportal inflammatory activity $(\mathrm{p}=0.94)$.

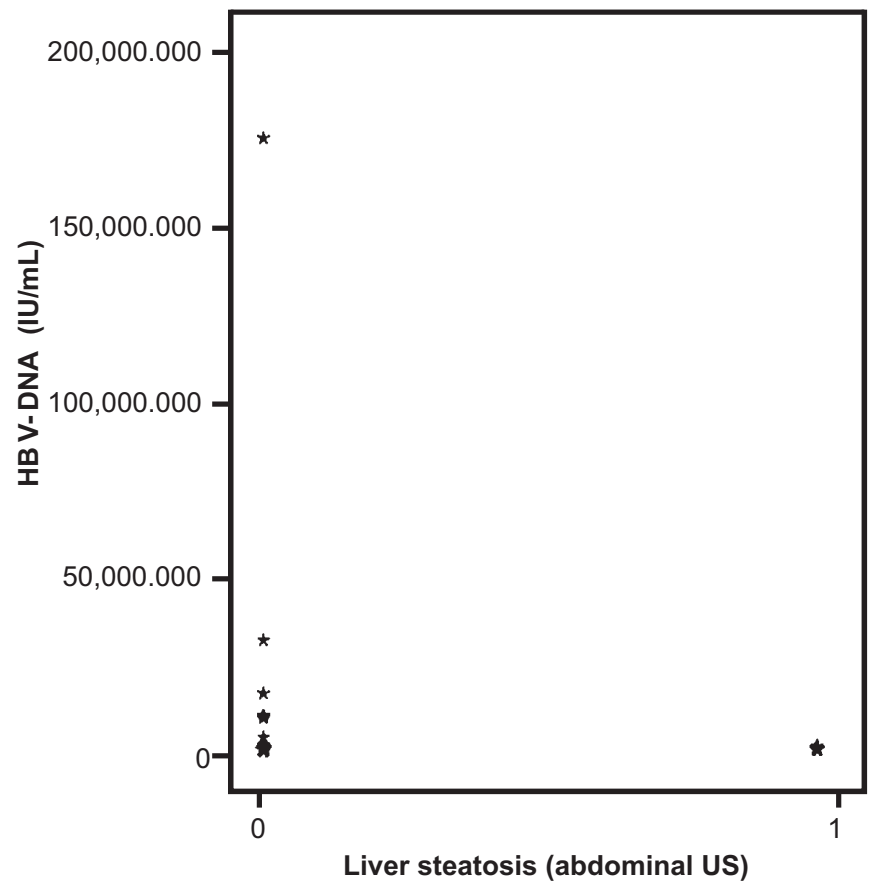

FIGURE 2 - Dispersion diagram illustrating the relationship between the HBV viral load and liver steatosis. HBV-DNA; hepatitis B virus-deoxyribonucleic acid; US: ultrasound.

The relationship between the HBV viral load and liver steatosis is illustrated in Figure 2.

Among those individuals with steatosis according to abdominal ultrasound, liver biopsy failed to confirm the diagnosis in one case (Table 3). Among those without steatosis according to abdominal ultrasound, five steatosis cases were confirmed during the liver biopsy. Abdominal ultrasound demonstrated the following accuracy parameters: accuracy $=0.692$, prevalence $=0.410$, sensitivity $=0.313$, specificity $=0.957$, positive predictive value $(\mathrm{PPV})=0.833$, and negative predictive value $(\mathrm{NPV})=0.667$. 
TABLE 3 - Distribution of 39 patients according to the presence of hepatic steatosis (HS) on ultrasonography and on liver biopsy.

\begin{tabular}{|c|c|c|c|c|c|c|}
\hline Characteristics & \multicolumn{2}{|c|}{$\mathrm{HS}(+) \mathrm{Bx}(\mathrm{n}=16)$} & \multicolumn{2}{|c|}{$\mathrm{HS}(-) \mathrm{Bx}(\mathrm{n}=23)$} & \multicolumn{2}{|c|}{ Total $(\mathrm{n}=39)$} \\
\hline HS $(+)$ on ultrasonography & 5 & 31.3 & 1 & 4.3 & 6 & 15.4 \\
\hline HS (-) on ultrasonography & 11 & 68.8 & 22 & 95.7 & 33 & 84.6 \\
\hline
\end{tabular}

HS: hepatic steatosis; Bx: liver biopsy. p-value $=0.033$.

\section{DISCUSSION}

Due to the global burden of obesity and increased body weight ${ }^{15}$, LS has become a common medical problem. In Brazil, the prevalence of obesity has increased over time, from $2.2 \%$ for men and $7.4 \%$ for women in 1975 to $8.8 \%$ for men and $13 \%$ for women in $2003^{16}$. In 2010, $16 \%$ of the Brazilian population was obese. The prevalence of obesity is predicted to increase to $46 \%$ by $2050^{17}$. In the United States, the prevalence of obesity is higher than in Brazil, involving $32 \%$ of adults and $17 \%$ of young persons ${ }^{18}$.

Among a sample of 90 Brazilian obese adolescents, the prevalence of LS on ultrasound was $15.5 \%{ }^{19}$. Hepatic ultrasound is a simple, noninvasive technique that is widely used in clinical practice to detect fatty infiltration of the $\operatorname{liver}^{20}$. Several studies have assessed the sensitivity and specificity of ultrasound for detecting LS. In these studies, the sensitivity ranged from $60 \%$ to $94 \%$ and the specificity from $84 \%$ to $97 \%{ }^{21-24}$. In a sample of 94 Brazilian individuals with elevated ALT, $40 \%$ presented LS on ultrasound, and both the BMI and history of diabetes were independently associated with the presence of $\mathrm{LS}^{25}$. Almost one-third of a sample of 2,287 American subjects evaluated by Browning et al. presented with LS according to magnetic resonance imaging (31\%). LS was associated not only with metabolic syndrome but also particularly with obesity and insulin resistance ${ }^{26}$.

In the present study, the presence of LS on abdominal ultrasound was associated with fasting insulin and total cholesterol, similar to findings previously reported by other authors in non-HBV patients ${ }^{25,27-29}$, indicating that LS is related to disordered metabolism of blood glucose and lipids. Although BMI data were available only in a small subset of patients $(\mathrm{n}=19)$, these data revealed a significant difference between the two study groups. Insulin resistance plays a central role in the pathogenesis of NAFLD. It has been demonstrated that obesity is associated with insulin resistance, leading to hyperinsulinemia, increased free fatty acid concentrations, and hyperglycemia. Insulin resistance leads to increased delivery of free fatty acids to the liver, increased fatty acid synthesis, and impaired release of triglycerides from the liver. These modifications cause triglycerides to accumulate in the hepatocyte ${ }^{30}$.

A recent experimental study revealed that adenovirus containing the HBV genome (Ad-HBV) up-regulated the expression of genes related to cholesterol metabolism in
HepG2 cells ${ }^{31}$, suggesting that HBV itself influences cholesterol metabolism. Nevertheless, the lipid profiles among individuals with chronic HBV remain a matter of debate in the literature. When HBV carriers were compared to HBsAg-negative individuals, the HBV carriers exhibited significantly lower odds ratios for hypercholesterolemia and hypertriglyceridemia, as well as higher LDL cholesterol levels9.

Biopsy-confirmed LS has been described in $18 \%-76 \%$ of chronic HBV patients ${ }^{32-36}$. The wide variation in the prevalence of LS in HBV carriers cannot be explained easily, as the patient characteristics do not appear to differ substantially among studies. No association was demonstrated between the histological findings of steatosis and dyslipidemia in the present study, similar to previous findings ${ }^{33-37}$. A possible limitation of the present study is that patients did not undergo biopsy specifically for this study. The data collection was retrospective, and the indication for liver biopsy was based on the viral load and ALT levels of the patients. Although this study design may indicate a source of bias, it represents a real-life approach to these cases. Nevertheless, as previously mentioned, abdominal ultrasound possesses high sensitivity and specificity for detecting LS, and in a sample of patients presenting more than $30 \%$ LS, the sensitivity and the specificity were shown to increase to $89.7 \%$ and $100 \%$, respectively ${ }^{24}$.

Among a sample of 350 individuals with chronic HBV in India, only the serum triglyceride level was found to be independently associated with LS according to multivariate analysis $^{36}$. Other studies have indicated that patients with chronic HBV infection and LS had significantly higher BMI and higher levels of fasting glucose, triglycerides, and total cholesterol than did those without steatosis ${ }^{11,13,32,35}$. Based on these findings, we can surmise that it is important to closely monitor the BMI, insulin resistance, and lipid profile in patients with chronic HBV, as well as in the general population, to prevent the occurrence of LS. However, considering that a substantial amount of fatty infiltration in the liver may contribute to the seroclearance of HBsAg, it has been shown that HBsAg carriers with mild LS did not present an increased likelihood of HBsAg seroclearance. However, moderate-to-severe LS has been associated with 3- to 4-fold increased odds of HBsAg seroclearance compared to those with no evidence of $\mathrm{LS}^{38}$.

No association was demonstrated between steatosis and either HBV DNA viral load or HBeAg status. Given the relatively small number of patients with viral load data $(\mathrm{n}=64)$, this finding does not necessarily exclude a role for 
HBV in mediating LS, and further studies that examine a larger cohort are needed to address this question. Some authors have found an association between viral load and the absence of steatosis ${ }^{11,32}$, and an inverse relationship between metabolic syndrome and chronic HBV has been demonstrated ${ }^{6}$. The reason why HBsAg-positive subjects are less prone to developing metabolic syndrome remains unclear. One possible explanation is that individuals with a high BMI and moderate-to-intense ultrasound grading of LS tend to clear HBsAg from their serum.

In the present study, the level of AST was associated with the presence of LS on abdominal ultrasound. Aminotransferases are serum markers of liver damage that are usually altered in the presence of $\mathrm{LS}^{39}$. Despite observing lower levels of AST among patients with steatosis, both study groups presented altered AST levels. The association between LS and advanced fibrosis was not evaluated in the present study; nevertheless, it has been shown that LS is less common in patients with advanced fibrosis, and lower AST levels have been observed in individuals with advanced fibrosis ${ }^{35}$.

Other possible limitations of the present study should be mentioned. Although the total number of patients included in the cohort was representative of the overall population, we examined possible associations between certain factors and LS, considerably reducing the number of subjects presenting particular variable combinations and, consequently, the power of the statistical tests. Although it is not a strict rule, maintaining a minimum of ten events per variable is recommended during logistic regression analysis. This recomendation is based on studies that showed increasing bias and variability, unreliable coverage of confidence intervals, and problems with model convergence as the events per variable declined below ten ${ }^{40-42}$. For this reason, these results need to be confirmed in a larger set of patients. Additionally, the study design was cross-sectional and did not include a longitudinal follow-up. The ultrasounds may not have been uniform in terms of operator and evaluation method, as this was not a prospective study. Indeed, the ultrasound results reflect a day-to-day medical practice in which one relies on ultrasound to initially define whether the patient presents with LS. As we have demonstrated, ultrasonography does not always match biopsy results perfectly. Data on alcohol ingestion, diet quality, and routine exercise were also lacking; therefore, an analysis of the effect of these variables on metabolic disease in this population was not possible. Another limitation of our study was the absence of a control group; nevertheless, our findings are comparable to previously published data.

The causes and significance of LS in HBV-related liver disease continues to be investigated. Individuals with LS present lower AST levels than do those without steatosis. The findings of the present study indicate that LS in HBV carriers appears to be a result of metabolic factors attributable to the host and related to insulin action rather than to viral factors; however, larger studies are needed to validate these findings. Therefore, it may be surmised that to prevent LS in patients with chronic HBV, AST and BMI should be periodically monitored and the blood glucose and lipid profiles should be controlled, in addition to educating these patients about healthy lifestyle, scientific dieting, and physical exercise.

\section{CONFLICT OF INTEREST}

The authors declare that there is no conflict of interest.

\section{REFERENCES}

1. Lavanchy D. Hepatitis B virus epidemiology, disease burden, treatment, and current and emerging prevention and control measures. J Viral Hepat 2004; 11:97-107.

2. Clark JM, Brancati FL, Diehl AM. Nonalcoholic fatty liver disease. Gastroenterology 2002; 122:1649-1657.

3. Harrison SA, Torgerson S, Hayashi PH. The natural history of nonalcoholic fatty liver disease: a clinical histopathological study. Am J Gastroenterol 2003; 98:2042-2047.

4. Machado MV, Cortez-Pinto H. Insulin resistance and steatosis in chronic hepatitis C. Ann Hepatol 2009; 8 (suppl I):67-75.

5. Li WC, Lee YY, Chen IC, Sun C, Chiu FH, Chuang CH. Association between the hepatitis $\mathrm{B}$ and $\mathrm{C}$ viruses and metabolic diseases in patients stratified by age. Liver Int 2013; 33:1194-1202.

6. Jan CF, Chen CJ, Chiu YH, Chen LS, Wu HM, Huang CC, et al. A population-based study investigating the association between metabolic syndrome and hepatitis $\mathrm{B} / \mathrm{C}$ infection (Keelung Community-based Integrated Screening study No. 10). Int J Obes (Lond) 2006; 30:794-799.

7. Kanel GC, Radvan G, Peters RL. High-density lipoprotein cholesterol and liver disease. Hepatol 1983; 3:343-348.

8. Cicognani C, Malavolti M, Morselli-Labate AM, Zamboni L, Sama C, Barbara L. Serum lipid and lipoprotein patterns in patients with liver cirrhosis and chronic active hepatitis. Arch Int Med 1997; 157:792-796.

9. Su TC, Lee YT, Cheng TJ, Chien HP, Wang JD. Chronic hepatitis B virus infection and dyslipidemia. J Formosan Med Assoc (Taiwan yi zhi) 2004; 103:286-291.

10. Liu PT, Hwang AC, Chen JD. Combined effects of hepatitis B virus infection and elevated alanine aminotransferase levels on dyslipidemia. Metabolism 2013; 62:220-225.

11. Zheng RD, Chen JN, Zhuang QY, Lu YH, Chen J, Chen BF. Clinical and virological characteristics of chronic hepatitis $\mathrm{B}$ patients with hepatic steatosis. Int J Med Sci 2013; 10:641-646.

12. Fan JG, Chitturi S. Hepatitis B and fatty liver: causal or coincidental? J Gastroenterol Hepatol 2008; 23:679-681.

13. Zheng RD, Xu CR, Jiang L, Dou AX, Zhou K, Lu LG. Predictors of hepatic steatosis in HBeAg-negative chronic hepatitis B patients and their diagnostic values in hepatic fibrosis. Int J Med Sci 2010; 7:272-277.

14. Gayotto LCC. Visão histórica e consenso nacional sobre a classificação das hepatites crônicas. Gastroenterol Endosc Digest 2000; 19:4.

15. Kopelman PG. Obesity as a medical problem. Nature 2000; 404:635-643

16. Monteiro CA, Conde WL, Popkin BM. Income-specific trends in obesity in Brazil: 1975-2003. Am J Public Health 2007; 97:1808-1812.

17. Rtveladze K, Marsh T, Webber L, Kilpi F, Levy D, Conde W, et al. Health and economic burden of obesity in Brazil. PloS One 2013; 8:e68785.

18. Ogden CL, Carroll MD, Curtin LR, McDowell MA, Tabak CJ, Flegal KM. Prevalence of overweight and obesity in the United States, 1999-2004. JAMA 2006; 295:1549-1555.

19. Fernandes MT, Ferraro AA, Azevedo RA, Fagundes Neto U. Metabolic differences between male and female adolescents with non-alcoholic fatty liver disease, as detected by ultrasound. Acta Paediatr 2010; 99:1218-1223.

20. Mehta SR, Thomas EL, Bell JD, Johnston DG, Taylor-Robinson SD. Noninvasive means of measuring hepatic fat content. World J Gastroenterol 2008; 14:3476-3483.

21. Joseph AE, Saverymuttu SH, al-Sam S, Cook MG, Maxwell JD. Comparison of liver histology with ultrasonography in assessing diffuse parenchymal liver disease. Clin Radiol 1991; 43:26-31. 
22. Foster KJ, Dewbury KC, Griffith AH, Wright R. The accuracy of ultrasound in the detection of fatty infiltration of the liver. Br J Radiol 1980; 53:440-442.

23. Saverymuttu SH, Joseph AE, Maxwell JD. Ultrasound scanning in the detection of hepatic fibrosis and steatosis. Br Med J (Clin Res Ed) 1986; 292:13-15.

24. Palmentieri B, de Sio I, La Mura V, Masarone M, Vecchione R, Bruno S, et al. The role of bright liver echo pattern on ultrasound B-mode examination in the diagnosis of liver steatosis. Dig Liver Dis 2006; 38:485-489.

25. Narciso-Schiavon JL, Schiavon LL, Carvalho-Filho RJ, Hayashida DY, Wang JH, Souza TS, et al. Clinical characteristics associated with hepatic steatosis on ultrasonography in patients with elevated alanine aminotransferase. Sao Paulo Med J 2010; 128:342-347.

26. Browning JD, Szczepaniak LS, Dobbins R, Nuremberg P, Horton JD, Cohen JC, et al. Prevalence of hepatic steatosis in an urban population in the United States: impact of ethnicity. Hepatol 2004; 40:1387-1395.

27. Cassader M, Gambino R, Musso G, Depetris N, Mecca F, Cavallo-Perin P, et al. Postprandial triglyceride-rich lipoprotein metabolism and insulin sensitivity in nonalcoholic steatohepatitis patients. Lipids 2001; 36: 1117-1124.

28. Hsiao PJ, Kuo KK, Shin SJ, Yang YH, Lin WY, Yang JF, et al. Significant correlations between severe fatty liver and risk factors for metabolic syndrome. J Gastroenterol Hepatol 2007; 22:2118-2123.

29. Venturi C, Zoppini G, Zamboni C, Muggeo M. Insulin sensitivity and hepatic steatosis in obese subjects with normal glucose tolerance. Nutr Metab Cardiovasc Dis 2004; 14:200-204.

30. Meek SE, Nair KS, Jensen MD. Insulin regulation of regional free fatty acid metabolism. Diabetes 1999; 48:10-14.

31. Li YJ, Zhu P, Liang Y, Yin WG, Xiao JH. Hepatitis B virus induces expression of cholesterol metabolism-related genes via TLR2 in HepG2 cells. World J Gastroenterol 2013; 19:2262-2269.

32. Minakari M, Molaei M, Shalmani HM, Mohammad Alizadeh AH, Jazi AH, Naderi $\mathrm{N}$, et al. Liver steatosis in patients with chronic hepatitis B infection: host and viral risk factors. Eur J Gastroenterol Hepatol 2009; 21:512-516.

33. Gordon A, McLean CA, Pedersen JS, Bailey MJ, Roberts SK. Hepatic steatosis in chronic hepatitis B and C: predictors, distribution and effect on fibrosis. J Hepatology 2005; 43:38-44.

34. Altlparmak E, Koklu S, Yalinkilic M, Yuksel O, Cicek B, Kayacetin E, et al. Viral and host causes of fatty liver in chronic hepatitis B. World J Gastroenterol 2005; 11:3056-3059.

35. Thomopoulos KC, Arvaniti V, Tsamantas AC, Dimitropoulou D, Gogos CA, Siagris D, et al. Prevalence of liver steatosis in patients with chronic hepatitis B: a study of associated factors and of relationship with fibrosis. Eur J Gastroenterol Hepatol 2006; 18:233-237.

36. Rastogi A, Sakhuja P, Kumar A, Hissar S, Jain A, Gondal R, et al. Steatosis in chronic hepatitis B: prevalence and correlation with biochemical, histologic, viral, and metabolic parameters. Indian J Pathol Microbiol 2011; 54:454-459.

37. Zamin Jr I, Mattos AA, Zettler CG. Nonalcoholic steatohepatitis in nondiabetic obese patients. Canadian J Gastroenterol 2002; 16:303-307.

38. Chu CM, Lin DY, Liaw YF. Does increased body mass index with hepatic steatosis contribute to seroclearance of hepatitis B virus (HBV) surface antigen in chronic HBV infection? Int J Obes (Lond) 2007; 31:871-875.

39. Paschos P, Paletas K. Non alcoholic fatty liver disease and metabolic syndrome. Hippokratia 2009; 13:9-19.

40. Concato J, Peduzzi P, Holford TR, Feinstein AR. Importance of events per independent variable in proportional hazards analysis. I. Background, goals, and general strategy. J Clin Epidemiol 1995; 48:1495-1501.

41. Peduzzi P, Concato J, Feinstein AR, Holford TR. Importance of events per independent variable in proportional hazards regression analysis. II. Accuracy and precision of regression estimates. J Clin Epidemiol 1995; 48:1503-1510.

42. Peduzzi P, Concato J, Kemper E, Holford TR, Feinstein AR. A simulation study of the number of events per variable in logistic regression analysis. J Clin Epidemiol 1996; 49:1373-1379. 